\title{
HUBUNGAN RIWAYAT PREMATUR DENGAN TUMBUH KEMBANG ANAK USIA SATU TAHUN
}

Keperawatan, Stikes Fort De Kock,

\author{
Rina Mariyana ${ }^{1}$
}

rinamariyana@fdk.ac.id

Submitted: 27-11-2018, Reviewer: 04-12-2018, Accepted: 17-12-2018

\begin{abstract}
ABSTRAK
Kelahiran prematur hingga saat ini masih menjadi masalah baik di negara maju maupun negara berkembang. Bayi yang terlahir prematur seringkali memberikan efek jangka panjang maupun jangka pendek. Dampak yang mungkin terjadi pada bayi yang lahir prematur adalah menurunnya kualitas hidup karena berisiko mengalami gangguan pada pertumbuhan dan perkembangan di kemudian hari. Penelitian ini bertujuan untuk mengetahui tumbuh kembang anak yang lahir prematur sampai usia 1 tahun. Jenis penelitian yang digunakan adalah kuantitatif menggunakan desain cross sectional. Teknik yang digunakan dengan total sampel sebanyak 30 responden. pada anak yang dilahirkan prematur, sampel yang diambil pada anak usia 1 tahun. Hasilnya terdapat perbedaan proporsi kejadian suspek keterlambatan perkembangan pada anak yang terlahir prematur ( $p$ value $=0,005$, OR 17). Anak yang terlahir prematur akan berisiko mengalami suspek keterlambatan perkembangan. Keterlambatan perkembangan yang dialami anak dilihat dari 4 aspek yaitu personal sosial, motorik halus, motorik kasar dan bahasa. Hasil yang lebih signifikan terdapat pada personal bahasa.
\end{abstract}

Kata kunci:Tumbuh, kembang, prematuritas, Anak

\section{ABSTRACT}

Premature births are still a problem in both developed and developing countries. Infant born prematurely often have long-term and short-term effects on their growth and development. The impact from the bebies born prematurely is decreased quality of life because increased of development cognitive and disruption to future growth and development. This study aims to determine the growth and development of children development in 1 year old who were born prematurely.The research used is quantitative using a cross sectional design. The technique used with a total sample of 30 respondents. in children born prematurely, samples taken in children aged 1 year. The result is a difference in the proportion of suspected cases of developmental delay in children who are premature born ( $p$ value $=0.005$, OR 17). Children who are born prematurely are at risk of experiencing developmental delay. The developmental delay experienced by children is seen from 4 aspects, namely personal social, fine motoric, gross motoric and language. More significant results are found in personal language.

Keywords: Growth, development, prematurity, Child 


\section{PENDAHULUAN}

Kematian anak menjadi indikator penting dalam menentukan tingkat kesejahteraan masyarakat, dimana tujuan dari Millenium Development Goals yaitu menurunkan angka kematian anak. Dari 184 negara menunjukkan bahwa rata-rata kelahiran bayi prematur sebesar 5\%-18\% (World Health Organization/ WHO, 2011). Di Indonesia sendiri data kementrian kesehehatan bayi prematur di indonesia 675.700 bayi. Menurut Blencowe et al. (2012) dalam 20 tahun terakhir terjadi peningkatan angka kematian bayi yang terlahir prematur. Bayi yang terlahir dalam kondisi berat rendah akan beresiko terhadap kematian neonatal (Depkes, 2005). Indonesia merupakan negara kelima dengan jumlah bayi prematur terbanyak didunia. (Yuliana, $\mathrm{R}$, 2017). Bayi mengalami kematian sebesar 6,5\% lebih besar dari bayi yang lahir normal dengan prevalensi BBLR sebesar 7,5 \% yaitu 496.000-900.00 bayi setiap tahunnya (Saraswati, E, 2006).

Kelahiran prematur berhubungan dengan terjadinya gangguan tumbuh kembang. Bayi yang terlahir prematur mempunyai fungsi tubuh yang masih belum baik, dari sistem peredaran darah, pernafasan dan kekebalan tubuh. Dampak lain yang terjadi pada bayi prematur adalah menurunnya kualitas hidup. Keterlambatan dalam pertumbuhan dan perkembangan pada anak merupakan masalah yang sangat sering kita jumpai di masyarakat namun untuk penanganan dari pertumbuhan dan perkembangan tersebut masih sangat belum memadai. Tumbuh kembang pada anak yang terlahir prematur belum mengalami perubahan ke arah yang lebih baik. Dengan penelitian ini diharapkan orang tua daopat memantau tumbuh kembang anak dengan memberikan stimulasi secara dini agar anak mampu berkembang sesuai dengan perkembangan dimana anak di usia satu tahu sudah bisa berjalan, bersosialisasi, mengucapkan bahasa walaupun belum terlalu jelas.

Penelitian terdahulu menunjukkan hasil perkembangan yang berbeda-beda pada setiap anak maka perlu detekni dini untuk menilai tumbuh kembang pada anak. (Soetjadmiko, 2001). Menurut penelitian Rijken 2007 mengatakan Bayi lahir prematur berisiko mengalami growth retardation keterlambatan yang dialami bayi dalam kondisi tumbuh kembangnya mencapai $32 \%$. Dimana tujuan dari penelitian ini adalah untuk mendeteksi secara dini pertumbuhan dan perkembangan anak agar tidak terjadi keterlambatan terhadap tumbuh kembang anak.

Dalam melakukan deteksi dini terhadap pertumbuhan serta perkembangan bagi anak sangat diharapkan peran perawat. Berdasarkan hal tersebut maka penelitian yang dirumuskan adalah "Bagaimanakah hubungan tumbuh kembang anak usia 1 tahun yang lahir prematur?".

\section{METODE}

Penelitian dengan metode kuantitatif yang menggunakan desain cross sectional dengan variabel independen adalah prematuritas dan variabel dependen adalah tumbuh kembang. Pengumpulan data dipilih 
berdasarkan kriteria inklusi sebagai berikut: 1) Anak berusia 1 tahun saat penelitian dilaksanakan yang memiliki riwayat lahir prematur; 2) Orang tua anak bersedia ikut berpartisipasi dalam penelitian.

Penelitian ini menggunakan Total sampling, dimana peneliti sudah menetapkan partisipan sesuai tujuan penelitian sejak awal(Afiyanti, \& Rachmawati, 2014; Arikunto, 2011).

Dengan jumlah anak yang sebesar 30 responden. Teknik pengambilan sampel yang digunakan adalah dengan purposive sampling. Pengambilan sampel pada penelitian ini menggunakan data primer dan data sekunder. Data primer diambil dengan melakukan kunjungan rumah meliputi data pertumbuhan dan perkembangan anak usia 1 tahun. Pengukuran perkembangan dengan menggunakan formulir Denver II. alat yang digunakan KPSP diterjemahkan dari keterlambatan perkembangan. (Damayani,2006).

Dengan skrining sejak dini, maka adanya penyimpangan keterlambatan dapat PDQ (Parent Developmental Questions) dikembangkan segera dideteksi sejak dini sehingga intervesi dapat dari DDST(Denver Developmental Screening Test). (Glascoe, 2005).

Penelitian ini menggunakan analisis univariat untuk menjelaskan atau mendeskripsikan karakteristik setiap variabel penelitian. Semua data dianalisis dengan tingkat kemaknaan $95 \% \quad(\alpha=0,005)$. Analisis data pada penelitian ini meliputi analisis deskripsif dan uji hipotesis. Pada analisis deskriptif, data dengan skala kategorik akan dinyatakan dalam distribusi frekuensi dan persentase. Sementara itu, data dengan skala kontinyu akan dinyatakan dalam rerata dan simpang baku.

Analisis bivariat dilakukan untuk membuktikan hipotesis dengan uji perbedaan proporsi serta menentukan besarnya hubungan variabel independen dan dependen. Uji statistik yang digunakan dalam penelitian ini adalah chi square. Hubungan antar variabel pada analisis bivariat digambarkan dengan analisis tabel silang $2 \times 2$. Analisis tabel silang ini menggunakan derajat kemaknaan sebesar 5\% $(p<$ $0,05)$ dengan tingkat interval kepercayaan 95\%. Hasil uji statistik ini dapat disimpulkan adanya hubungan dua variabel tersebut bermakna atau tidak bermakna.

\section{HASIL PENELITIAN}

\begin{tabular}{lcc}
\hline \multicolumn{1}{c}{ Variabel } & $\begin{array}{c}\text { Frekuensi } \\
(\mathbf{n}=\mathbf{3 0})\end{array}$ & $\begin{array}{c}\text { Prosentase } \\
(\mathbf{\%})\end{array}$ \\
\hline Pertumbuhan & & \\
Gangguan pertumbuhan & 2 & 6,7 \\
Normal & 28 & 93,3 \\
\hline
\end{tabular}

\section{A. Analisis Univariat}

Tabel 1

Distribusi Pertumbuhan Anak

Tabel 1 menunjukkan bahwa 2 dari 30 responden bayi dengan prematur sebesar $(6,7 \%)$ mengalami gangguan pertumbuhan dan 93,3\% pertumbuhan anak normal.

Tabel 2

Distribusi Perkembangan Anak

\begin{tabular}{lcc}
\hline \hline \multicolumn{1}{c}{ Variabel } & $\begin{array}{c}\text { Frekuensi } \\
(\mathbf{n = 3 0 )}\end{array}$ & $\begin{array}{c}\text { Prosentase } \\
(\mathbf{\%})\end{array}$ \\
\hline Perkembangan & & \\
Suspek keterlambatan & 17 & 56,7 \\
Normal & 13 & 43,3 \\
\hline
\end{tabular}

Tabel 2 menunjukkan bahwa 17 dari 30 responden bayi dengan prematur sebesar $56, \%$ mengalami suspek 
keterlambatan dan $\quad 43,3 \%$ anak perkembangannya normal. Anak yang mengalami perkembangan berdasarkan 4 sektor perkembangan dari tabel berikut:

Tabel 3

Distribusi Empat Sektor Perkembangan $(n=30)$

\begin{tabular}{lcc}
\hline \multicolumn{1}{c}{ Variabel } & Frekuensi (n) & Prosentase (\%) \\
\hline Personal sosial & & \\
Suspek keterlambatan & 2 & 6,7 \\
Normal & 28 & 93,3 \\
& & \\
Motorik Halus & 5 & \\
Suspek keterlambatan & 25 & 16,7 \\
Normal & & 83,3 \\
& & \\
Bahasa & 13 & 43,3 \\
Suspek keterlambatan & 27 & 56,7 \\
Normal & & \\
& & \\
Motorik Kasar & 4 & 13,3 \\
Suspek keterlambatan & 26 & 86,7 \\
Normal & & \\
\hline
\end{tabular}

Tabel 3 menunjukkan bahwa suspek keterlambatan perkembangan bahasa memiliki prosentase terbesar yaitu $(43,3 \%)$ diikuti oleh motorik halus $(16,7 \%)$, motorik kasar $(13,3 \% \%)$ dan personal sosial $(6,7 \%)$

\section{B. Analisis Bivariat}

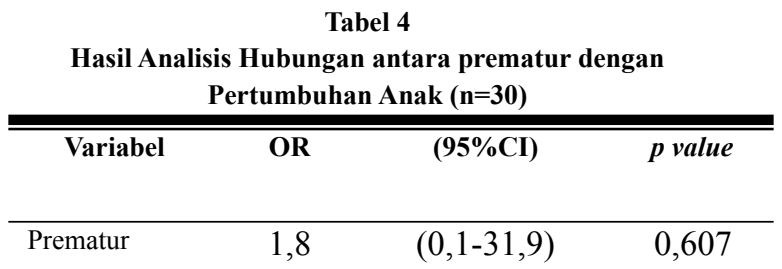

Tabel 4 menunjukkan bahwa dari hasil uji statistik nilai $p$ value $=0,607$ $(>0,05)$, maka dapat disimpulkan bahwa tidak ada perbedaan proporsi kejadian gangguan pertumbuhan pada kejadian prematur.

Tabel 5

Hasil Analisis Hubungan antara prematur dengan Pekembangan Anak $(n=30)$
Tabel 5 menunjukkan bahwa hasil uji statistik nilai $p$ value $=0,005(<$ 0,05), maka dapat disimpulkan bahwa ada perbedaan proporsi kejadian keterlambatan perkembangan pada kejadian prematur.

\section{PEMBAHASAN}

\section{A. Hubungan antara prematur dengan Pertumbuhan Anak}

Dalam hasil analisa dimana menilai hubungan antara kejadian prematuritas dengan pertumbuhan menunjukkan bahwa tidak ada perbedaan kejadian gangguan pertumbuhan anak yang lahir prematur dengan kejadian prematur. Menurut Wong et al. (2009), berat badan anak yang lahir normal saat berusia 1 tahun adalah 3 kali berat badan lahir. pertumbuhan anak yang lahir prematur tetap mengalami masalah selama 3 sampai 5 bulan. Menurut penelitian yang dilakukan oleh wonokrobo 2006 menjelaskan bahwa tinggi badan anak yang lahir prematurpada tahun pertama berada di bawah normal dan tahun kedua tinggi anak berlangsung pesat, dan terjadi peningkatan berat badan setiap bulan.

Orang tua lebih ekstra memberikan perhatian kepada anak dengan kondisi anak yang terlahir dengan kondisi berat badan rendah sehingga pertumbuhan anak lebih dipicu dengan asupan makanan yang berdampak pada kenaikan berat badan anak yang lebih signifikan dibanding saat anak lahir.

\section{B. Hubungan antara prematur} dengan Perkembangan Anak

\begin{tabular}{cccc}
\hline \hline Variabel & OR & $\mathbf{( 9 5 \% C I )}$ & p value \\
\hline Prematur & 17,143 & $(1,79-163,8)$ & 0,005 \\
\hline
\end{tabular}


Dalam hasil analisa dimana menilai hubungan antara kejadian prematuritas dengan perkembangan menunjukkan bahwa bahwa ada perbedaan kejadian keterlambatan perkembangan pada prematur. Sejalan dengan penelitian yang dilakukan oleh Soubasi, V., Velikos, K., Michalettou, I., Papadopoulou, V., Sarafidis, K., Nakas, C., \& Drossou-Agakidou, V. (2014). Melakukan penelitian pada anak usia sekolah didapatkan data bahwa anak yang terlahir prematur mengalami keterlambatan dalam neurologgis, dan tingkat kogntif yang rendah. Penelitian Zwiten, Brand And wit, 2003 mengatakan bahwa perkembangan mental anak mengalami keterlambatan, keterlambatan yang di alami anak terkait perkembangan bicara dan bahasa, konsentrasi dan prilaku. Menurut Raybaud, C., Ahmad, T., Rastegar, N., Shroff, M., \& Al Nassar, M. (2013) mengattakan bahwa perkembangan otak pada anak dengan lahir prematur sering kali tidak stabil.

Menurut Greene, M. F., M.D. (2002). Mengatakan bahwa anak yang lahir dengan berat badan rendah akan mengalami gangguan neurologis dan mengalami keterlambatan perkembangan serta IQ rendah. Fal ini akan berdampak pada perkembangan otaknya. Perkembangan otak pada janin terjadi di intrauterin pada usia kehamilan 34-36 minggu terjadi pertumbuhan akson dan dendrit (Volpe, 2008), sementara pada bayi yang terlahir prematur perkembangan otak terjadi di ekstrauterin.

Pada saat intrauterin pematangan sistem saraf ini tidak terjadi yang dapat mengakibatkan gangguan secara fungsional (De Graaf \& Hadders, 2006).
Gangguan yang terjadi pada otak anak berpengaruh pada perkembangan bayi prematur. Menurut Zhumakanova, K., Abeouva, B., Kenzhebayeva, G. A., \& Kuzgibekova, A. B. (2014). Perkembangan bayi premattur mengalami keterlambatan. Keterbaharuan dalam penelitian ini diharapkan orang tua mampu melakukan stimulasi kepada anak secara dini dengan mengetahui gangguan perkembangan yang terjadi pada anak dimana didapatkan hasil penelitian ini anak mengalami keterlambatan bahasa dimana anak belum mampu dan belum jelas dalam menyebutkan fokalnya bahkan menyebutkan "mama" saja belum jelas.

Dari hasil penelitian yang telah dilakukan didapatkan anak mengalami perkembangan terbesar pada keterlambatan motorik halus, motorik kasar, dan personal sosial. Hal ini sejalan dengan penelitian yang dilakukan Pramudito (2004) menyatakan bahwa prematuritas sebagai faktor risiko gangguan perkembangan usia 6-36 bln. keterlambatan bicara merupakan ekspresif awal dari gangguan bahasa (Carter, 2013). Apabila terjadi kelainan pada salah satu dari jalannya impuls ini maka akan terjadi kelainan bicara. Dengan mengetahui perkembangan apa yang lebih mendasar akibat kelahiran anak dengan prematur peneliti dapat memberikan informasi terkait dengan stimulasi yang dapat diberikan pada anak dengan usia satu tahun. Mutilasi motorik kasar yang bisa diberikan pada anak satu tahun yaitu ; stimulasi merangkak, mengajak anak bermain bola, berjalan, berdiri dan naik tangga. Stimulasi halus dengan bermain 
menyusun kubus, dan menggambar. Stimulasi bahasa yang bisa dilakukan yaitu: meniru kata-kata, bicara dengan boneka, dan bernyanyi. Stimulasi pada perkembangan sosialisasi yaitu dengan nina bobok, cilukba, makan sendiri, dan mengambil mainan sendiri.

\section{KESIMPULAN}

Kesimpulan yang dapat diambil dari penelitian ini adalah pertumbuhan anak usia 1 tahun sebesar $6,7 \%$ anak mengalami gangguan pertumbuhan dan $56,7 \%$ anak mengalami suspek gangguan perkembangan. Hasil analisis menunjukkan bahwa ada perbedaan proporsi kejadian gangguan perkembangan pada bayi prematur

\section{UCAPAN TERIMA KASIH}

Ucapan terimakasih disampaikan kepada seluruh partisipan yang telah bersedia menjadi responden dan membantu dalam proses penelitian, ucapan terima kasih kepada mahasiswa pkl yang telah membantu membagikan kuesioner termasuk kepada tim jurnal karena telah mereview hingga artikel ini diterbitkan.

\section{DAFTAR PUSTAKA}

Adriana, D. (2011). Tumbuh kembang dan terapi bermain pada anak. Jakarta: Salemba Medika.

Blencowe, H., Cousens, S., Oestergaard, M., Chou, D., Moller, A. B., Narwal, R., . . Lawn, J. E. (2012), National, regional and worldwide estimates of preterm birth., 9, p. 2162-2172.

Damayanti M, D. (2006) Kuesioner Pra Skrining Perkembangan (KPSP) Anak.
Dahlan, M. S. (2012). Langkah-langkah membuat proposal penelitian bidang kedokteran dan kesehatan. Cetakan kedua. Jakarta: CV. Sagung Seto.

De Graaf-Peters, V. B, Hadders-Algra, M. (2006)', Ontogeny of the human central nervous system: What is happening when?, Journal Ea, p. 82: 257-266.

Glascoe (2005) 'Parents' Concerns About Children's One to Under Six Years Old', Journal of the Medical Develop Association Thailand., J88(1):, pp. 86-90.

Greene, M. F., M.D. (2002). Outcomes of very low birth weight in young adults.The New England Journal of Medicine, 346(3), 146-8. Retrieved fromhttps://search.proquest.com/doc view $/ 223932892$ ? accountid $=38628$

Gutbrod, T. et al. (2000) 'E V ects of gestation and birth weight on the growth and development of very low birthweight small for gestational age infants: a matched group comparison', pp. 208-214.

Notoatmojo, S. (2010). Metodologi penelitian kesehatan. Jakarta: Rineka Cipta.

Rijken, M., Stoelhorst, G. M., Martens, S. E., van Zwieten, P. H., Brand, R., Wit, J. M., \& Veen, S. (2003) 'Mortality and neurologic, mental, and psychomotor development at 2 years in infants born less than 27 week' gestation: The leiden follow up project on prematurity', Pediatric, 112(2), pp. 351-358. Available at: http://www.ncbi.nlm.nih.gov.

Raybaud, C., Ahmad, T., Rastegar, N., Shroff, M., \& Al Nassar, M. (2013). The premature brain: Developmental and

lesional anatomy. Neuroradiology, 55, 23-40. 
doi:http://dx.doi.org/10.1007/s00234013-1231-0

Soubasi, V., Velikos, K., Michalettou, I., Papadopoulou, V., Sarafidis, K., Nakas, C., \& Drossou-Agakidou, V. (2014).

PO-0391 Longitudinal development of language skills in premature infants using bayley scales of infant development-iii. effect of parental education. Archives of Disease in Childhood, 99 doi:http://dx.doi.org/1 0.1136/archdischild-2014$307384.1037 \mathrm{~s}$

Soedjatmiko (2001) 'Deteksi Dini Gangguan Tumbuh Indonesia'; Kembang Balita. Sari Pediatri, 3, p. 175-188.

Velpe (2006) 'Neurology of the newborn.', Philadelphia: Elsevier Saunders.

WHO (2012) Born too soon, the global action report on preterm birth, jakarta EGC. http://www.who.int

Wong, D. L., Hockenberry, M., Wison, D., Winkelstein, M. L., \& Schwartz, P. (2009) Buku ajar keperawatan pediatrik., jakarta EGC.

wonokromo, k. (2006) 'profil tumbuh kembang anak yang lahir prematur sampai usia kurang dari tiga tahun di kelurahan jagir ', pp. 1-2.
Yuliana, (2017) ', faktor yang mempengaruhi kematian bayi prematur di indonesia, 1(November). Zhumakanova, K., Abeouva, B., Kenzhebayeva, G. A., \& Kuzgibekova, A. B. (2014). PO0725 Psychoneurological development of extremely premature babies. Archives of Disease in Childhood, 99doi:http://dx.doi.org/1 0.1136/archdischild-2014307384.1360 